\title{
REVISTAMARACANAN
}

Dossiê

\section{Narrativas Locais e Memória Coletiva: estudo de caso de três monumentos da cidade de Vitória da Conquista}

\author{
Local Narratives, Collective Memory and Cultural Heritage: case study about \\ three monuments of the city of Vitoria da Conquista
}

Recebido em: 17 fev. 2019.

Aprovado em: 09 mar. 2019.

Gerlane Bezerra Rodrigues*

Universidade Federal do Rio de Janeiro, Brasil

Juliana Rodrigues Morais**

Universidade Federal Fluminense, Brasil

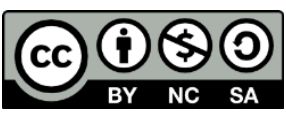

Este artigo é um desdobramento da dissertação de Mestrado Monumentos de Vitória da Conquista: Patrimônio Cultural e Discursos de Memórias (UNIRIO, 2018), projeto que contou com o financiamento do Conselho Nacional de Desenvolvimento Científico e Tecnológico - CNPq, Brasil.

* Doutora e Mestre em Memória Social pela Universidade Federal do Estado do Rio de Janeiro; Especialista em Memória, História e Historiografia; graduada em História pela Universidade Estadual do Sudoeste da Bahia. Atualmente é professora de História do município de Rio das Ostras, Rio de Janeiro. (geo2.rodrigues@hotmail.com)

ORCID iD: https://orcid.org/0000-0001-5845-0977

CV Lattes: http://lattes.cnpq.br/2222585148472420

** Doutoranda do Programa de Pós-graduação em Sociologia da Universidade Federal Fluminense (UFF). Mestra e graduada em Sociologia pela UFF. (julianamorais@id.uff.br)

ORCID iD: https://orcid.org/0000-0003-0974-1617

CV Lattes: http://lattes.cnpq.br/0622911035676862 


\title{
Resumo
}

Este artigo tem por objetivo discutir a construção da memória coletiva em Vitória da Conquista (BA) a partir de três monumentos representativos da coleção dessa cidade: a peça em homenagem aos Bandeirantes, a peça em homenagem a Nossa Senhora da Vitória, padroeira da cidade, e a peça em homenagem aos Índios Mongoiós. A pesquisa constatou que no contexto de redemocratização do Brasil, após a década de 1980, houve um aumento no erguimento e na promoção de monumentos nesta cidade. Esse fenômeno se evidencia, sobretudo, com o erguimento de peças escultóricas que apresentam temas e narrativas ligados às memórias antes desprestigiadas, ou excluídas do tecido social urbano, como por exemplo, o monumento aos índios. Nessa perspectiva, constatamos, pois, que os monumentos da cidade constroem um espaço patrimonial polifônico onde atuam múltiplas memórias num campo de disputas, conflitos, contradições, rupturas e, também, de continuidades. Podemos dizer que essa prática se expressa como uma afirmação social do poder local, num contexto nacional de autonomização política da municipalidade decorrente, entre outros fatores, das prerrogativas constitucionais instituídas pela Constituição Federal de 1988, as quais redefiniram a concepção de cultura, ampliaram o conceito de patrimônio cultural e, por conseguinte, evidenciaram (re)leituras da Memória e da História da cidade.

Palavras-chave: Narrativas Locais. Memória Coletiva. Monumentos.

\begin{abstract}
This article aims to discuss the construction of collective memory in Vitória da Conquista (BA) from three representative monuments of the collection of this city: the piece in homage to the Bandeirantes, the piece in homage to Our Lady of Victory, patroness of the city, and the piece in homage of the Mongoiós Indians. The research found that in the context of redemocratization in Brazil, after the 1980s, there was an increase in the building and promotion of monuments in this city. This phenomenon is evidenced, above all, by the construction of pieces that present themes and narratives linked to previously discredited memories, or memories excluded from the urban social tissue, such as the monument to the Indians. From this perspective, we find that the monuments of the city create a polyphonic patrimonial space where multiple memories work in a field of disputes, conflicts, contradictions, ruptures and also continuities. We can say that this practice is expressed as a social affirmation of local power, in a national context of political autonomy of the municipality outcome, among other factors, from the constitutional prerogatives established by the Federal Constitution of 1988, which redefined the concept of culture, broadened the concept of cultural heritage and, consequently, evidenced (re)readings of the Memory and History of the city.
\end{abstract}

Keywords: Local Narratives. Collective Memory. Monuments. 


\section{Memória Coletiva: um olhar sobre a cidade}

Ao observamos as cidades contemporâneas brasileiras, os espaços públicos como, praças, jardins, ruas e avenidas é possível verificar a construção da memória coletiva, ${ }^{1}$ cujo suporte de fundamentação encontra-se, sobretudo, no erguimento e na promoção de monumentos. ${ }^{2}$ Como objetos de rememoração, esses monumentos participam do universo das representações, cuja função reside em perpetuar algo que os grupos sociais e/ou os indivíduos não desejam que seja esquecido. Dessa maneira, a representação que carrega os monumentos pode transcender, no plano simbólico, a condição humana da morte. ${ }^{3}$ Por demarcarem pontos fixados em determinados espaço urbanos, tais monumentos transitam por diversas temporalidades e estão expostos a inúmeras interpretações, algumas vezes, atualizam-se no tempo. Não obstante, seu conteúdo narrativo sempre estará vulnerável a dialética da lembrança e do esquecimento, fenômenos indissociáveis da construção da memória. Nessa dinâmica, os monumentos, ao serem sacralizados pela memória, carregam o atributo de semióforos (palavra de origem grega que significa expor, trazer a frente) e assim afirmam seu valor simbólico do passado. Com efeito, os semióforos fazem parte das coleções definidas por Krzystof Pomian como um conjunto de objetos que se encontram acumulados com um propósito determinado de garantir uma comunicação do visível com o invisível. O visível é parte integrante do mundo real, enquanto o invisível é aquilo que não se vê, que se encontra fora do mundo imediato. Segundo este autor, esse fenômeno da comunicação está presente em todas as sociedades, ultrapassando as fronteiras do tempo, estando presente em todas as classes de objetos acumulados e também em todas as relações entre os objetos de uma coleção e seus destinatários. $^{4}$

Para assegurar que um conjunto de objetos se constitui como uma coleção, Pomian elege e articula alguns critérios, a saber: (i) a exposição ao olhar seria um critério fundamental e universal, o qual estabelece a relação entre o visível e o invisível; (ii) os objetos devem estar

\footnotetext{
1 Não utilizamos o conceito de "memória coletiva" de acordo com a distinção proposta por alguns teóricos, como, por exemplo, Jacques Le Goff - que usa o toma para as sociedades sem escrita (GONDAR, J. Memória individual, memória coletiva, memória social. Morpheus - Revista Eletrônica em Ciências Humanas, ano 08, n. 13, 2008). Utilizamos, antes, alinhados ao proposto por Maurice Halbwachs, identificando-o como uma memória construída pelos grupos sociais. Cf.: HALBWACHS, Maurice. A memória coletiva. São Paulo: Centauro, 2006.

${ }^{2}$ Cf.: RIEGL, Alöis. O culto moderno aos monumentos: sua essência e sua gênese. Goiânia: Ed. UGG, 2006. As referências conceituais sobre monumentos levam em consideração os pressupostos teóricos e conceituais deste autor.

3 Entretanto, cabe ressaltar que não é raro o desconhecimento dos indivíduos acerca do conteúdo narrativo de origem destas peças erigidas nas cidades. Isso não esvazia o papel simbólico ou icônico desempenhado por estes objetos, pois, algumas vezes, são atribuídos outros sentidos e/ou eles demarcam o espaço cotidiano na cidade e servem de marco para encontros, referência de identificação de lugares, entre outros.
}

${ }^{4}$ POMIAN, Krizystof. Coleção. (Verbete). In: Enciclopédia Einaudi. Vol. 1: Memória - História. Lisboa: Imprensa Nacional - Casa da Moeda, 1984, p.51-86. 
fora do circuito das atividades econômicas; (iii) estes devem estar protegidos e; além disso, (iv) as coleções devem se acumular em lugares fechados, preparados para a exposição ao olhar. A despeito deste último critério, consideramos a cidade como um espaço fechado tendo em vista a sua municipalidade. É nesse sentido que os monumentos de Vitória da Conquista podem ser considerados objetos de uma coleção, sendo a cidade o próprio sujeito colecionador. Ela possui um acervo de dezesseis monumentos, cujas narrativas de conteúdo histórico são objetos de comunicação com o invisível, ou seja, com o passado da sociedade que as produziu. Esses objetos (peças escultóricas/monumentos) cumprem, portanto, todos os critérios definidos por Pomian que caracterizam o conceito de coleção. Na cidade, a observância da prática de erigir e promover peças escultóricas se constitui como parte integrante de um poder simbólico que atravessa temporalidades diversas, realizando conexões entre o passado, o presente e o futuro. ${ }^{5}$

\subsection{Vitória da Conquista: quadro síntese da coleção dos monumentos da cidade}

A cidade de Vitória da Conquista, situada no interior da Bahia, apesar de possuir uma singularidade inerente ao seu povo e à sua cultura, apresenta características semelhantes a outras cidades brasileiras, provenientes de processos comuns de construção histórica. Assim como outras cidades e territórios, ela foi construída e dominada a partir de conflitos, contradições, guerras e massacres aos povos "nativos". Essas práticas serviam a interesses particulares inseridos num contexto mais amplo que correspondia à história da colonização da América pelos europeus. Estas sociedades, ao garantirem o domínio do espaço físico, tentavam garantir também o domínio do espaço simbólico. E, para isso, se utilizavam de diversos mecanismos de poder simbólico - tais como a língua, a religião, os costumes, etc. Desse processo de dominação, surge - após a Revolução Francesa - a necessidade de se ressignificar, preservar e erigir monumentos, suportes físicos com os quais determinados grupos sociais hegemônicos podiam articular ora a lembrança, ora o esquecimento. É nesse cenário, em que se inscreve a construção dos monumentos urbanos que fazem relação tanto com a história quanto com a memória das cidades, que emerge o fenômeno estatuamania, originalmente instituído na França do século XIX, no contexto de consolidação do projeto de Estado-nação moderno.

Apresentaremos, a seguir, um quadro que reúne a coleção de monumentos da cidade de Vitória Conquista distribuídos segundo um eixo cronológico e outro tipológico. A metodologia aplicada nessa pesquisa foi seguida a partir das ideias trabalhadas pelos pesquisadores Marcelo Abreu e Paulo Knauss, membros do Laboratório de História Oral e

\footnotetext{
${ }^{5}$ POMIAN, Krzystof. [Título]. Coleção. Op. cit., p. 51-86.
} 
Imagem da Universidade Federal Fluminense (LABHOI-UFF). ${ }^{6}$ Neste texto, a título de amostragem da pesquisa, apresentaremos um quadro tipológico/cronológico dos monumentos e cuja análise se deu, sobretudo, mediante a investigação desse inventário.

Tabela 1 - Coleção de monumentos da cidade de Vitória Conquista, BA.

\begin{tabular}{|c|c|c|c|c|c|c|c|}
\hline Tipologia & 1920 & 1940 & 1950 & 1980 & 1990 & 2000 & 2008 \\
\hline Busto & & & & & & $\begin{array}{l}\text { 1- Luiz E. } \\
\text { Magalhães }\end{array}$ & \\
\hline $\begin{array}{l}\text { Estátua } \\
\text { Alegórica }\end{array}$ & & & & $\begin{array}{l}\text { 1- Imigrantes } \\
\text { 2-Cristo }\end{array}$ & $\begin{array}{c}\text { 1- Pracinhas } \\
\text { da Segunda } \\
\text { Guerra } \\
\text { Mundial } \\
\end{array}$ & & \\
\hline Estátua & & & & & & $\begin{array}{c}\text { 2- Nossa } \\
\text { Senhora das } \\
\text { Vitórias }\end{array}$ & \\
\hline Ícone & 1- Cruzeiro & & & & & & \\
\hline Obelisco & & $\begin{array}{c}1- \\
\text { Bandeirantes }\end{array}$ & $\begin{array}{l}\text { 1- Getúlio } \\
\text { Vargas }\end{array}$ & & & & \\
\hline Escultura & & & & $\begin{array}{c}\text { 3- Dez } \\
\text { Mandamentos } \\
\text { 4- Bíblia }\end{array}$ & $\begin{array}{l}\text { 2- Mortos da } \\
\text { Ditadura - } \\
\text { Embasa }\end{array}$ & $\begin{array}{l}\text { 3- Índios- } \\
\text { 4-Glauber } \\
\text { Rocha }\end{array}$ & \\
\hline Marcos & & & & & & $\begin{array}{l}\text { 5- Dona Jacy } \\
\text { Flores }\end{array}$ & $\begin{array}{c}1- \\
\text { Monumento } \\
\text { ao Príncipe } \\
\text { Maximiliano } \\
\end{array}$ \\
\hline Total & 1 & 1 & 1 & 4 & 3 & 5 & 1 \\
\hline
\end{tabular}

A coleção começou a ser erigida no município num período de tempo que corresponde a 85 anos, entre os séculos XX e XXI. Na década de 1920 foi erigido o primeiro monumento na cidade, trata-se de um ícone, cujo tema é religioso. Na década de 1930, não há registros de monumentos. Na década de 1940 tem-se o obelisco em homenagem aos bandeirantes, João Goncalves da Costa e João da Silva Guimarães, fundadores da cidade, essa peça escultórica foi erguida pelo poder público. Na década de 1950, outro obelisco é erigido pelo poder público, em homenagem ao presidente da república, Getúlio Dorneles Vargas, na rodovia que liga a Serra do Maçal, a 18 km de Conquista. Não há registros de monumentos das décadas de 1960 e de

${ }^{6}$ Para realização deste trabalho, organizamos um inventário dos monumentos da cidade de Vitória da Conquista. Este procedimento metodológico se deu mediante uma pesquisa na cidade e sobre a cidade, fundamentada em diversas fontes (referências bibliográficas, jornais, documentos institucionais da Coroa Portuguesa, conversas informais, trabalho fotográfico, etc.). O trabalho resultou num relatório, com um banco de dados e resumos sobre as imagens urbanas. É importante destacar que a análise do inventário levou em consideração os dados mais relevantes do ponto de vista da supremacia ou predominância das peças, tendo em vista o propósito da discussão do texto. Neste estudo de caso, buscamos estabelecer tendências gerais, definidas por um levantamento quantitativo e qualitativo de informações, dados e referências conceituais. 
1970, contexto do período do Regime Militar no Brasil. Já na década de 1980, com o processo de redemocratização do país, houve um aumento significativo no número de monumentos erguidos na cidade. Foram erigidas quatro peças: duas esculturas e duas estátuas. Neste contexto, a temática religiosa foi retomada com o erguimento de monumentos: a estátua do Cristo Crucificado, na Serra do Periperi, erguido pelo poder público, o monumento à Bíblia e o monumento aos Dez Mandamentos. Estes dois últimos foram erigidos por membros de Igrejas Protestantes. Nessa mesma década é erigido um monumento aos imigrantes nordestinos, erguido pelo poder público. Já na década de 1990, foram erigidos três monumentos: uma estátua que representa os Pracinhas da II Guerra Mundial, promovida pelo poder público, e duas esculturas: a primeira é a peça que faz homenagem aos mortos e desaparecidos baianos do Regime Militar no Brasil, erigida por segmentos da sociedade, e a segunda homenageia uma obra do Estado de fornecimento de água à cidade, erguido pelo poder público. A partir do ano de 2000, tem-se um acréscimo no erguimento dos monumentos urbanos com a promoção de cinco peças: (i) uma escultura em homenagem aos índios, erigida por segmentos da sociedade; (ii) um busto em homenagem ao político baiano Luiz Eduardo Magalhães, erguido pelo poder público; (iii) um marco erguido por particulares em homenagem à matriarca dona Jacy Flores; (iv) uma escultura em homenagem ao cineasta Glauber Rocha, erguida pelo poder público e; (v) uma estátua em homenagem a Nossa Senhora da Vitória, promovida pela Igreja Católica. Por último, no ano de 2008, foi erigido, por particulares, um marco em homenagem ao príncipe alemão Maximilian de Wied-Neuwied.

Das dezesseis peças que compõem a coleção de monumentos da cidade, sete foram obras erguidas por iniciativa do Governo, o que corresponde a um total de quase metade das promoções. Isso é bastante significado na medida em que observamos a construção de uma memória oficial pela iniciativa estatal. A Igreja foi responsável por quatro promoções e erguimentos. O que é também significativo, pois corresponde a mais da metade das peças do Governo. Isso nos leva a perceber o movimento de construção de memórias promovido pelas duas instituições. Elas foram responsáveis pelo erguimento e promoção de onze peças. As cinco peças restantes foram erigidas pela iniciativa da sociedade e doações de particulares. Ficou evidenciado na promoção das peças que a sociedade se mobilizou timidamente em relação às instituições públicas. Esses monumentos se fixam na paisagem urbana e adentram pelos caminhos que dão acesso a outras localidades distantes da cidade. Como objetos públicos e obras de rememoração intencionais, esses monumentos se inscrevem no contexto da história e da memória, ambas em constante movimento. Por isso, não podemos dizer que esses monumentos estão fixados do ponto de vista simbólico, pois a intenção e a promoção dessas peças estarão sujeitas as novas leituras pela sociedade na qual elas se inserem.

\section{Diálogos entre os monumentos: Bandeirantes, Nossa Senhora da Vitória e Índios Mongoiós}


Da coleção de monumentos da cidade de Vitória da Conquista, três peças parecem dialogar, fazendo uma interseção com narrativas, temas e personagens relacionadas ao período colonial e ao passado de fundação da cidade, a saber: (i) o monumento aos Bandeirantes, (ii) o monumento a Nossa Senhora da Vitória e (iii) o monumento aos Índios Mongóis.

No que se refere ao primeiro monumento, trata-se de uma homenagem aos bandeirantes portugueses que conquistaram a região onde hoje está situado o município de Vitória da Conquista. Consta. Em algumas fontes e documentos relativos à fundação da cidade, que, na segunda metade do século XVIII, o superintendente de Minas Novas, comarca da Bahia, Pedro Leolino Mariz, em nome da Coroa Portuguesa, designou uma expedição para conquistar o Sertão da Ressaca, ${ }^{7}$ território situado entre Minas Gerais e Bahia. A Bandeira era chefiada por André Rocha Pinto, integrava a expedição o português João da Silva Guimarães. O território percorrido e explorado pelos desbravadores correspondia aos trechos banhados pelos rios de Contas, Pardo e São Matheus. ${ }^{8}$ Entre as décadas de 1744 a 1752 o português João da Silva Guimarães tentou entrar e dominar essa região, que era povoada por algumas nações indígenas como os Mongoiós, os Imborés e os Patachós. Obteve algumas conquistas, porém, sofreu consecutivas derrotas nos embates com os índios Mongoiós, na região onde hoje se situa o Planalto de Conquista. Somente trinta anos mais tarde, em 1782, João Gonçalves da Costa (genro de João da Silva Guimarães), com uma Bandeira organizada com aproximadamente 50 homens, entra em luta com os índios Mongoiós e vence a guerra. De acordo com as narrativas locais, a vitória lusitana no interior baiano foi legitimada pela interferência de uma santa, conhecida pelos portugueses por Nossa Senhora da Vitória. ${ }^{9}$ A narrativa sobre esse episódio teria sido disseminada por Laurinda Silva, neta de um escravo de João Gonçalves da Costa, conhecido por tio Nagô. ${ }^{10}$ Segundo tal narrativa, João Gonçalves teria prometido a santa de erguer uma igreja em homenagem a ela no local da aldeia dos Mongoiós, caso vencesse aquela batalha contra os índios. O bandeirante saiu vitorioso e,

\footnotetext{
7 O termo "Sertão da Ressaca" aparece nos documentos administrativos da Coroa Portuguesa do século XVIII, que fazem referência ao processo de domínio do interior da Bahia. Nestes documentos, Sertão da Ressaca, compreende genericamente uma área do interior que inclui a atual região onde está situado o município de Vitória de Conquista, Bahia. ALMEIDA, Eduardo Castro de. Inventário dos documentos relativos ao Brasil existentes no Arquivo de Marinha e Ultramar. Anais da Biblioteca Nacional. Lisboa, 1910-1912, v. XXXII- XXXIV; Bahia, 1763- 1786.

8 MEDEIROS, R. A Edição critica e anotada de: TORRES, T. L. O Município da Vitória. Vitória da Conquista, BA: Museu Regional da Vitória da Conquista; Universidade Estadual do Sudoeste da Bahia, 1996.

${ }^{9}$ Segundo a tradição, os portugueses teriam invocado a santa e obtiveram a primeira vitória e fundaram a localidade que hoje se chama Bairro da Vitória. O nome da santa foi alterado para Nossa Senhora das Vitórias. Em alguns documentos mais antigos encontramos o nome da santa escrito sem ser no plural, em outros mais recentes o nome já aparece no plural.

${ }^{10}$ Aníbal Viana narra, na Revista Histórica de Conquista, que Laurinda Silva, neta de Tio Nagô que residia em Vitória da Conquista, na casa de dona Maria Vitória dos Santos Silva, contava histórias que foram transmitidas por Tio Nagô. Segundo Laurinda, ele morava na antiga Rua do Beco Sujo, hoje, Rua Ernesto Dantas, havia vivido até os 110 anos, foi escravo de João Goncalves da Costa e teria testemunhado alguns episódios e ouvido do próprio Gonçalves histórias envolvendo o bandeirante, a santa e os índios. VIANA, A. Lopes. Revista Histórica de Conquista. Vitória da Conquista, BA: Edição Jornal de Conquista, 1982.
} 
algum tempo depois, em 1803, ele doa um terreno para a construção da Igreja de Nossa Senhora da Vitória na localidade onde antes estava fixada a aldeia dos Mongoiós. ${ }^{11} \mathrm{O}$ Arraial da Conquista - como era conhecida antigamente a atual cidade - foi se constituindo em torno do espaço doado para a construção dessa igreja. Somente em 1823 foi inaugurada a igreja com o nome da santa Nossa Senhora da Vitória (que só foi concluída vinte e cinco anos mais tarde, em 1848). Em 1840, o arraial passa a categoria de Vila e, em 1891, a Imperial Vila da Vitória passou à categoria de cidade, recebendo o nome de Conquista. ${ }^{12}$

Com o crescimento urbanístico da cidade, que se verificou em torno da igreja, foram tomadas algumas medidas para preservar esse espaço. Em 1896, foi editado um código de posturas que dispõe da organização urbanística da cidade nas proximidades da Igreja Matriz reafirmando o poder institucional:

O terreno da praça da Matriz, no alinhamento das casas, é destinado à edificação de casas e jardins. Ninguém poderá tê-lo fechado por muro ou cerca. Pena de [cinquenta mil réis] de multa ou seis dias de prisão (art. $30^{\circ}$ );

Conservar as frentes das casas e prédios rebocados e caiados (art. $28^{\circ}$ );

Ninguém poderá edificar na cidade casa coberta de palha (art. $36^{\circ}$ ), ou com altura inferior a vinte palmos (art. $31^{\circ}$ );

Os jardins da praça matriz serão fechados por grades de ferro e no alinhamento das casas de maneira a oferecer vistas à curiosidade pública (art. $30^{\circ}$, parágrafo 2);

Fica proibido amarrar-se animal encilhado ou não no passeio das casas. Pena de [cinco mil réis] de multa ou um dia de prisão (art. 450).

Atualmente, nesse centro histórico, encontram-se preservadas antigas casas e casarões, edificações que mantém elementos e traços da arquitetura colonial portuguesa do século XIX. ${ }^{13}$

\footnotetext{
${ }^{11}$ Os documentos de doação do terreno para construção da igreja estão no Cartório do $2^{\circ}$ Oficio da cidade da Vitória da Conquista, BA. Ver, também, um resumo do texto na: Revista História de Conquista, Vitória da Conquista (BA), vol. I, p. 49-57, [s.d.]. A cidade recebeu o nome de Vitória da Conquista somente em 1943.

12 LIMA, J. M. Memorial sobre o Estado da Bahia. Salvador: Topografia e encadernação do Diário da Bahia, 1893, p. 440.

${ }^{13}$ Algumas dessas propriedades têm uma função social que as difere do passado, onde antes eram bens privados, hoje se tornaram bens públicos, adquiridos pelo poder municipal, foram transformados em espaços que, em princípio, têm um caráter democrático, como o museu regional, a biblioteca pública, o centro cultural e o conservatório de música.
} 
Figura 1- Imagem da Igreja Matriz de Nossa Senhora das Vitória.

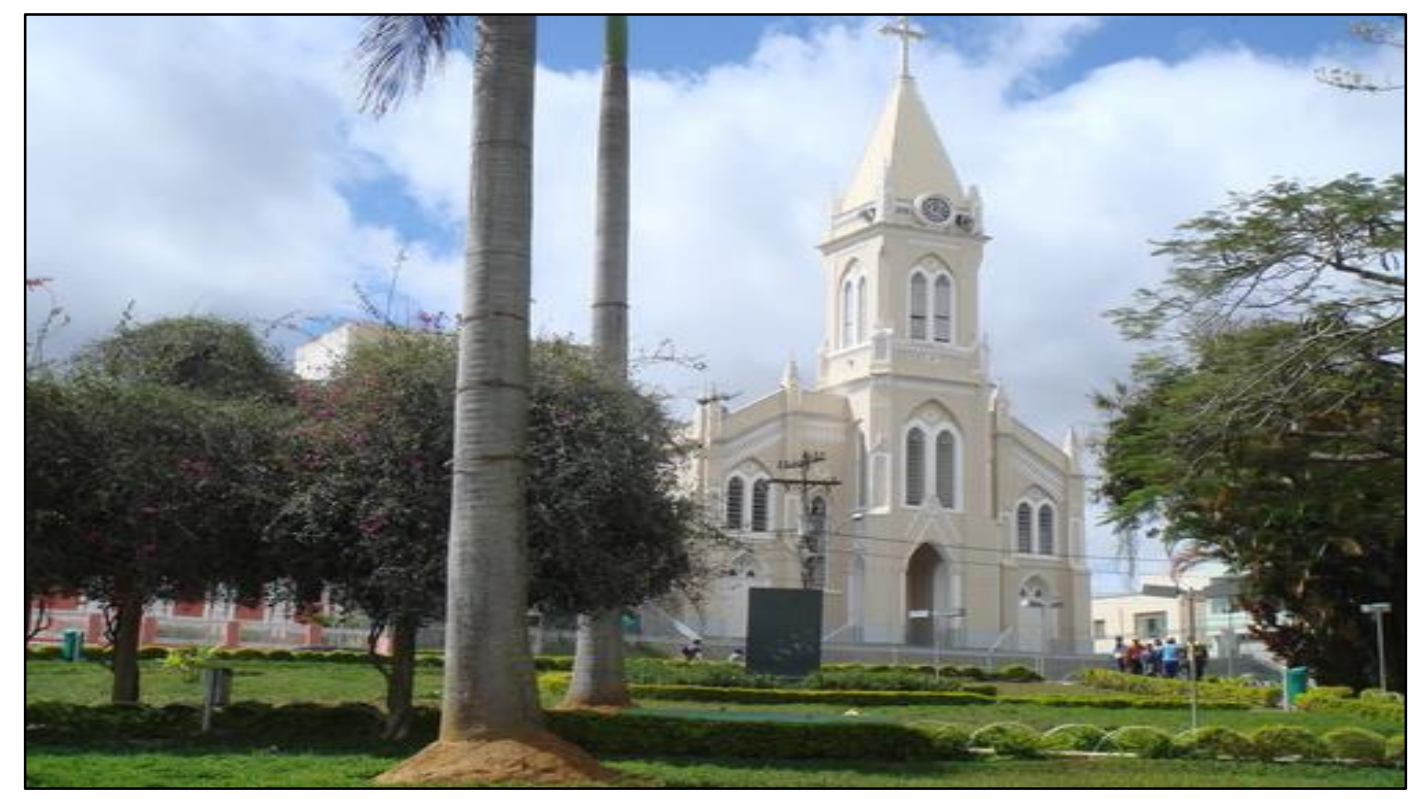

Fonte: Arquivo pessoal das autoras.

A cidade se expandiu a partir da Igreja Matriz e tem como parte valorizada, do ponto de vista de seu espaço urbano, a Praça Nove de Novembro, onde está erigido o primeiro monumento que presta homenagem aos fundadores do município - os bandeirantes João da Silva Guimarães e João Gonçalves da Costa.

Figura 2- Monumento em homenagem aos bandeirantes.

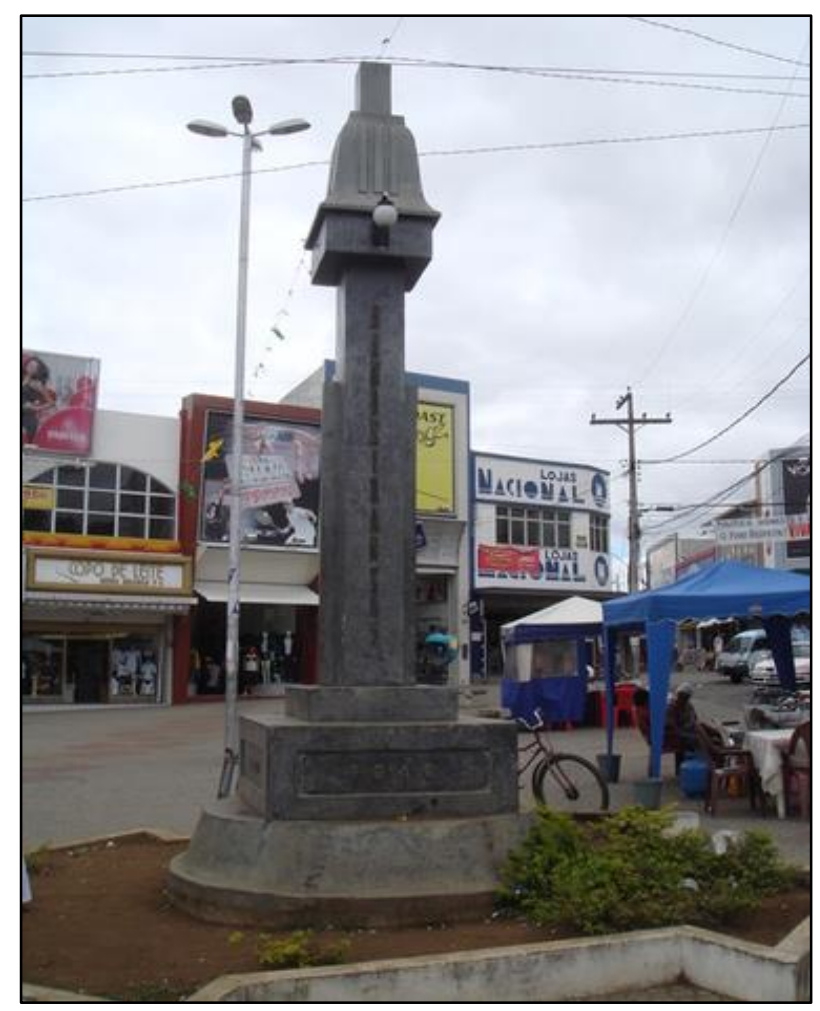

Fonte: Arquivo Pessoal das Autoras. 
O obelisco acima é composto de granito, com placas de identificação e grafia em bronze. Faz referência a memória local, mas está vinculado à memória nacional dos Bandeirantes. É possível compreender a partir das proposições apresentadas por Paulo Knauss que a base narrativa desse monumento, erigido pela iniciativa e promoção do Estado, estabelece uma relação, na qual se produz um vínculo de gratidão da sociedade para com o Estado. Ainda segundo o autor, nessa relação simbólica camuflam-se as contradições e os conflitos sociais entre o Estado e a sociedade civil. ${ }^{14}$ A construção dessa memória exerce uma função primordial de preservar a lembrança em torno dos laços de coesão social de determinados grupos. Estes laços, por sua vez, afirmam e/ou fortalecem a identidade desses grupos sociais.

Para Maurice Halbwachs, a identidade é construída e reforçada pela memória a partir dos laços de coesão social e de pertencimento grupal e se afirmam com base nas lembranças fortalecidas graças às narrativas, que, por sua vez, fundamentam-se por meio das comemorações públicas de acontecimentos que marcaram a história coletiva. Neste contexto a cidade é, por excelência, um espaço de memória coletiva. Ao materializar referências significativas do passado, a partir dos monumentos e das comemorações, os grupos sociais constroem um passado comum. ${ }^{15}$

o espaço é uma realidade que dura: nossas impressões se sucedem umas às outras, nada permanece em nosso espírito e não compreenderíamos que seja possível retomar o passado se ele não estivesse conservado no ambiente material que nos circunda. ${ }^{16}$

Dessa forma, a imagem da paisagem urbana oferece um sentido de estabilidade, que se traduz pela concretude dos espaços solidificados em jardins, praças, monumentos, casas, ruas, avenidas etc. Esses espaços socialmente construídos garantem um retorno seguro a uma dimensão no tempo que é conhecida, o passado. Essa relação traz, em si, a impressão de continuidade e de segurança em algo que não está exposto a grandes mudanças. Ainda de acordo com Halbwachs:

Não é muito fácil modificar as relações que se estabelecem entre as pedras e os homens [...]. Quando um grupo humano vive por muito tempo em um lugar adaptado a seus hábitos, não apenas a seus movimentos, mas também seus pensamentos se regulam pela sucessão das imagens materiais que os objetos exteriores representam para ele [...] As pedras e as matérias não oferecem resistência. Os grupos resistirão e, neles, você irá deparar com a resistência, se não das pedras, pelo menos de seus arranjos antigos. ${ }^{17}$

Halbwachs atribui umas das formas de resistência da memória coletiva ao espaço, como, por exemplo, as imagens espaciais. Ele nos mostra a relação que se estabelece entre as imagens e os indivíduos no domínio subjetivo. Segundo o autor, é nessa relação que surge um

\footnotetext{
14 KNAUSS, P. (coord.) Cidade vaidosa: imagens urbanas do Rio de Janeiro. Rio de Janeiro: 7 Letras, 1999.

${ }^{15}$ HALBWACHS, Maurice. A memória coletiva. São Paulo: Centauro, 2006.

${ }^{16}$ Ibidem, p. 170.

${ }^{17}$ Ibidem, p. 163.
} 
vínculo de segurança e continuidade; mesmo que a cidade sofra uma destruição e seja reconstruída, o que já foi estabelecido no âmbito desse espaço social com a dimensão do pensamento, das marcas e das lembranças dos grupos sociais poderá resistir. A resistência toma a forma de fragmentos do passado que se tornam memórias coletivas.

Reafirmando certa continuidade da memória coletiva hegemônica tem-se o segundo monumento. Trata-se da estátua em homenagem a Nossa Senhora da Vitória, uma peça em bronze maciço com pedestal de granito. A peça encontra-se erigida num local bastante prestigiado, em frente à praça principal da cidade, ao lado da Igreja Matriz que leva o nome da santa. A imagem se liga à tradição memorialista de fundação do município: uma narrativa de intervenção da santa em favor dos portugueses (bandeirantes) na guerra de domínio do território contra os índios Mongoiós. Essa intervenção seria motivada por uma promessa feita pelo bandeirante João Gonçalves da Costa à santa, caso vencesse a guerra.

Figura 3 - Monumento em homenagem a Nossa Senhora das Vitória.

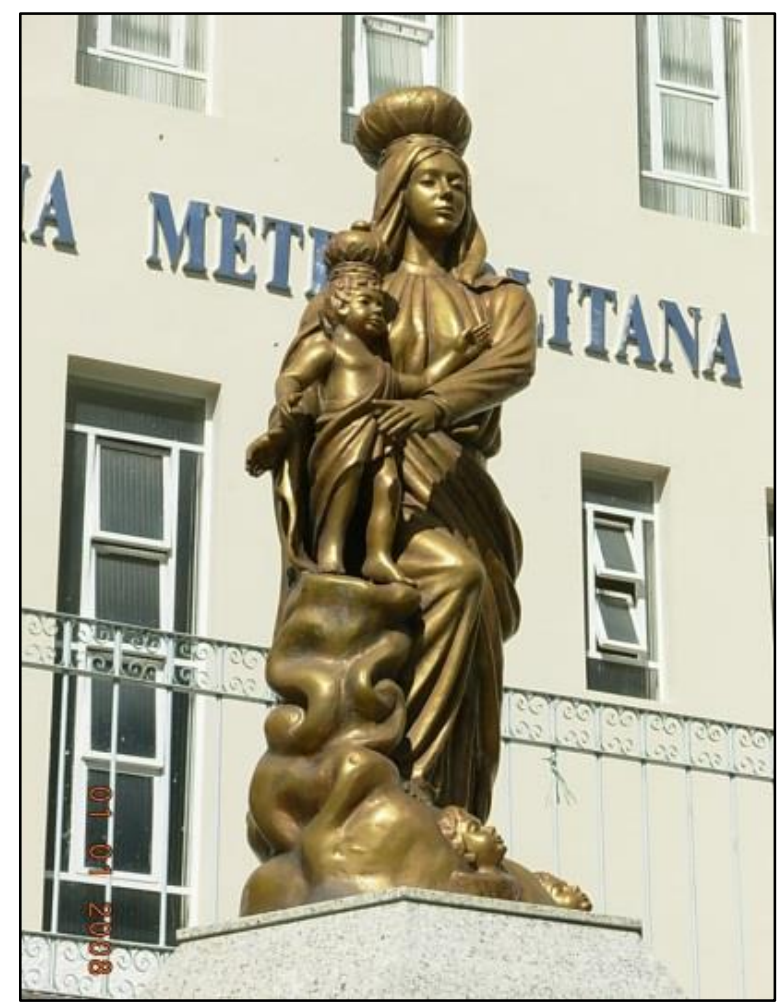

Fonte: Arquivo Pessoal das Autoras.

De acordo com Ruy Medeiros, o nome da cidade é uma homenagem aos bandeirantes portugueses que, segundo a tradição, venceram a batalha de conquista do território contra os índios, com a intercessão de Nossa Senhora da Vitória. Para Medeiros, se aceitarmos essa tradição passada de geração a geração da interferência da santa na guerra, escondemos alguns fatos para justificar outros. Ou seja, admitir que os portugueses pagaram uma promessa a santa significa aceitar que Nossa Senhora da Vitória estava contra os índios, e que 
os sertanistas venceram porque apresentaram méritos perante à santa. ${ }^{18}$ De todo modo, cabe observar que esse discurso da tradição não se fundamenta numa perspectiva dos grupos indígenas, mas sim, numa perspectiva cristã ocidental, vinculada a uma memória religiosa institucional.

$\mathrm{Na}$ contemporaneidade, ainda se faz presente esta memória que traduz a versão de fundação da cidade sob a proteção e a intervenção da santa. Com recorrência, essa versão pode ser encontrada em diversas fontes, principalmente, nos jornais da cidade. Com efeito, o jornal local Diário do Sudoeste da Bahia traz a seguinte matéria:

\section{Conquista: uma cidade assentada nas terras da Igreja}

Depois de apelos, invocando o nome de Nossa Senhora das Vitórias, o que motivou os soldados de sua Bandeira a investir, até a vitória final, contra os índios Mongoiós, o mestre de campo João da Silva Guimarães prometera que seria erguida uma capela dedicada à Santa. Promessa que só fora cumprida mais tarde, [...] ergue-se a capela de Nossa Senhora das Vitórias e, em volta, nascia também a cidade [...] A Igreja Católica participa no papel de senhorio direto das transações de compra e venda dos imóveis de Conquista, enquanto uma grande parte dos terrenos da cidade prevalece o domínio útil, em que os proprietários são alienantes. A posição de senhorio direto, que é na verdade o dono da terra foi concedida à igreja nos tempos remotos da fundação da cidade, pelo bandeirante João Gonçalves da Costa. Esse era um costume relativamente comum à época, uma vez que entre os objetivos da conquista de novas terras estava também a ideia de difundir o cristianismo, 'salvando as almas dos índios, transformando-os em cristãos'. Vencida a Batalha, a promessa foi cumprida. A capela à Santa foi levantada e usando como referencial o ponto um pouco abaixo de onde, hoje, está localizada a Catedral de Nossa Senhora das Vitórias (Padroeira da cidade), o desbravador deu à igreja uma légua (6 quilômetros) de terra. ${ }^{19}$

Essa versão da história fundacional da cidade faz menção a uma memória discursiva construída a partir de outros discursos pré-estabelecidos, como por exemplo, a narrativa memorialista de Laurinda. ${ }^{20}$ Esta narrativa é descrita pelo jornalista Aníbal Viana, na Revista Histórica de Conquista:

O capitão João da Costa, de facão em punho, lutava com muita coragem com os selvagens e eis que entre a folhagem surgiu uma índia muito diferente das outras, pela beleza fisionômica. O capitão aproximou-se para capturá-la e a índia corria a sua frente pelo mato, desde o lugar de nome Batalha, onde foi travada a luta, até o lugar da grande aldeia dos Mongoiós. Aí, a índia deu a frente ao Capitão, e ele reconheceu nela a imagem de Nossa Senhora. O Capitão ficou apavorado, estatelado com a visão, e fincou o facão no chão, ajoelhou-se e disse: aqui levantarei a Vossa Igreja, e a índia desapareceu. ${ }^{21}$

\footnotetext{
18 MEDEIROS, R. H. Nossa Senhora da Vitória e o povo. Jornal A Tarde, Vitória da Conquista (BA), 15 maio 1980 , p. 15.

${ }^{19}$ Diário do Sudoeste da Bahia, Vitória da Conquista (BA), 9 nov. 1998, p. 6-33. Grifos nossos.

${ }^{20}$ Cabe ressaltar que a história de interferência da santa na guerra da cidade de Vitória da Conquista entre os índios e os bandeirantes foi escrita no século XX, mas, segundo a fonte narradora (Laurinda), foi uma história de que ela tomou conhecimento pelo seu Tio Nagô no século XIX. Não se sabe, contudo, quando esta narrativa foi disseminada. O que apontamos neste trabalho é a evidência da construção dessa memória.

21 VIANA, Aníbal Lopes. Revista histórica de Conquista. Vitória da Conquista, BA: Edição Jornal de Conquista, 1982, p. 15.
} 
Assim, compreendemos que esta versão da história da cidade segue uma linha que visa se naturalizar no, já dito historicamente, fenômeno que contribui para construção de uma memória religiosa. Em outros termos, esse discurso se apresenta como uma continuidade de outros discursos e narrativas, que, segundo a tradição, foram construídos desde a fundação da vila, no século XVIII. Essa versão ainda se mantém no contexto social dos séculos XX e XXI, conforme apresenta a matéria do jornal Diário do Sudoeste da Bahia com data do ano 2000:

O município de Vitória da Conquista possui um forte aspecto religioso. Talvez isso se deva ao próprio surgimento da cidade e da fé de um bandeirante que dedicou a uma santa a sua vitória contra os índios mongoiós. Na verdade, foi a invocação ao nome de Nossa Senhora das Vitórias que motivou os soldados a investir, até a vitória final, contra os índios. Segundo os historiadores, o mestre de campo João Guimarães prometeu que seria erguida uma capela dedicada à santa, o que se concretizou em 1803.22

A marca desse pensamento civilizatório ocidental cristão, como um discurso legitimador do empreendimento português, é uma questão ainda presente na memória da sociedade conquistense. Podemos observar a tentativa de cristalização da memória hegemônica - da Igreja - a partir da construção discursiva produzida pela memória religiosa que se manifesta do seguinte modo: (i) nos fragmentos de jornais que trazem a construção da memória religiosa de fundação da cidade feita pelo discurso alinhado à Igreja Católica e; (ii) nessa mesma instituição a qual mantém um forte traço de poder que sobrevive no discurso e se reproduz no imaginário social, no que diz respeito à memória da fundação da cidade. ${ }^{23}$ Com efeito, o Cardeal da cidade, Dom Climério, no jornal local O Sertanejo, em 1970, faz menção ao passado trazendo a lembrança da consagração da cidade à santa:

Uma vez mais, desde 1783, estamos a comemorar o dia 15 de agosto. Mudaram-se sensivelmente os tempos, usos e costumes bem diversos andam do que o foram outrora; às antigas gerações de bravos outras se somaram e se multiplicaram, de tal modo que o arraial se fez cidade e a cidade, metrópole, cheia de brilho e de esperanças. Não se apagou, porém, na consciência da gente o reconhecimento de que Conquista, uma vez por todas à Mãe de Deus consagrada, é trono Seu, para sempre. Razão por que A evocamos hoje, como antes, e lhe prestamos tributo de veneração. ${ }^{24}$

Reforçando essa narrativa, a cidade comemora todos os anos o dia de Nossa Senhora da Vitória, que perpetua uma memória local, a qual se dissemina e ganha estatuto de verdade pela ritualização dos festejos e celebrações em homenagem à santa que é a padroeira da cidade. Esse ritual de celebração acontece no município há mais de duzentos anos. Na contemporaneidade, estes festejos marcam o calendário oficial da cidade, consagrado como feriado municipal, os quais começam com uma alvorada de fogos às cinco horas da manhã,

\footnotetext{
22 Diário do Sudoeste da Bahia, Vitória da Conquista (BA), 2000. Grifos nossos. O Jornal traz um equivoco com relação ao nome do bandeirante da narrativa de intervenção da santa na guerra da conquista. Segundo a tradição memorialista e demais fontes consultadas, o bandeirante que faz a promessa à santa se chamava João Gonçalves da Costa, genro de Guimarães.

${ }^{23}$ Esta memória pertence a uma tradição oral lusitana e foi recorrente no período colonial no Brasil.

24 Dom Climério, Bispo Diocesano de Vitória da Conquista. O Sertanejo, Vitória da Conquista (BA), 15 ago. 1970. Grifos nossos. Matéria extraída do jornal sobre a festa de Nossa Senhora da Vitória.
} 
seguida de grande procissão pelas principais ruas da cidade, culminando numa grande missa ao ar livre na Praça Principal, no local onde, num passado remoto, havia a antiga aldeia dos índios Mongoiós. Podemos dizer que essa prática ritualística de celebração e homenagem à santa atribui à cidade uma identidade religiosa, católica, herdeira de uma tradição lusitana, pois a retomada da memória alicerçada pelas celebrações e narrativas do passado se reforça num elo que permite reafirmar uma tradição como um discurso verdadeiro. ${ }^{25}$

De acordo com Paul Ricoeur, comemorar traz a função social de reviver coletivamente a memória de um acontecimento considerado como ato fundador. ${ }^{26}$ Nessa prática, evidencia-se o objetivo de sacralizar os valores e ideais de uma sociedade ou de certos grupos sociais. Assim, a comemoração à santa se constitui num momento de coesão social destes grupos e afirmação de uma identidade coletiva, que corresponde à exteriorização da memória coletiva, na qual se apresenta uma narrativa de fundação da cidade.

Contrapondo-se à construção dessa memória em evidência na cidade, tem-se o terceiro monumento: uma peça escultórica em homenagem aos índios Mongoiós, erigida quase sessenta anos depois do erguimento do monumento em homenagem aos bandeirantes e cinco anos antes do monumento à santa. O contexto do erguimento do monumento em homenagem aos índios, no ano de 2000, foi caracterizado por uma grande mobilização no cenário nacional em torno das raízes do Brasil. Naquele momento, os principais meios de comunicação anunciavam slogans comemorativos do aniversário de 500 anos de Brasil, numa dada tentativa de valorização do passado. É desse cenário de discussão política e cultural, ligado às questões da cidadania, do direito à memória e da identidade nacional, que o monumento aos índios foi erigido em Vitória da Conquista. A peça foi financiada por um grupo social em parceria com o setor privado e entidades não governamentais. André Cairo (descendente de povos indígenas e idealizador do monumento) escreveu uma carta, a qual segue um fragmento:

Com espírito inundado de essência indígena, relato, abaixo, a história do Monumento.

Desde 1992, o Movimento Contra a Morte Prematura vinha reivindicando, das autoridades, a construção de um monumento que viesse homenagear o índio. Realizamos diversas atividades, oficiamos a prefeitos, câmara de Vereadores, deputados e o desinteresse foi evidente. Mas continuamos insistindo e buscamos subsídios com empresas privadas e conseguimos construir a obra, oferecendo ao poder executivo para que instalasse na Pça. Tancredo Neves, antigo Jardim das Borboletas, onde, ali, existe um cemitério indígena, em que índios foram exterminados, massacrados brutalmente por Bandeirantes. [...] Para nossa decepção, não houve interesse por nenhum órgão, nem a prefeitura autorizou a instalação do monumento naquele local, alegando poluir o visual, diante do que ali já existia. Porém, discordamos sumariamente. Então, o prefeito solicitou de André Cairo que escolhesse outro local. Como sinal de protesto, ele escolheu o terraço de um prédio de 8 andares, mas resolveu mudar de ideia, instalando o

\footnotetext{
${ }^{25}$ A despeito das diferenças que constroem as bases narrativas e a memória destes dois monumentos (dos bandeirantes e da santa) ambos, enquanto produtos sociais, servem para afirmação simbólica de uma memória oficial que foi construída desde o período colonial.
}

${ }^{26}$ RICOEUR, Paul. Entre mémoire et I'histoire. Projet, Paris, n. 248, 1996. 
monumento na Pça. Caixeiros Viajantes, a qual passou a ser identificada, por muitos, como Praça do Índio. ${ }^{27}$

Figura 4 - Monumento em homenagem aos índios.

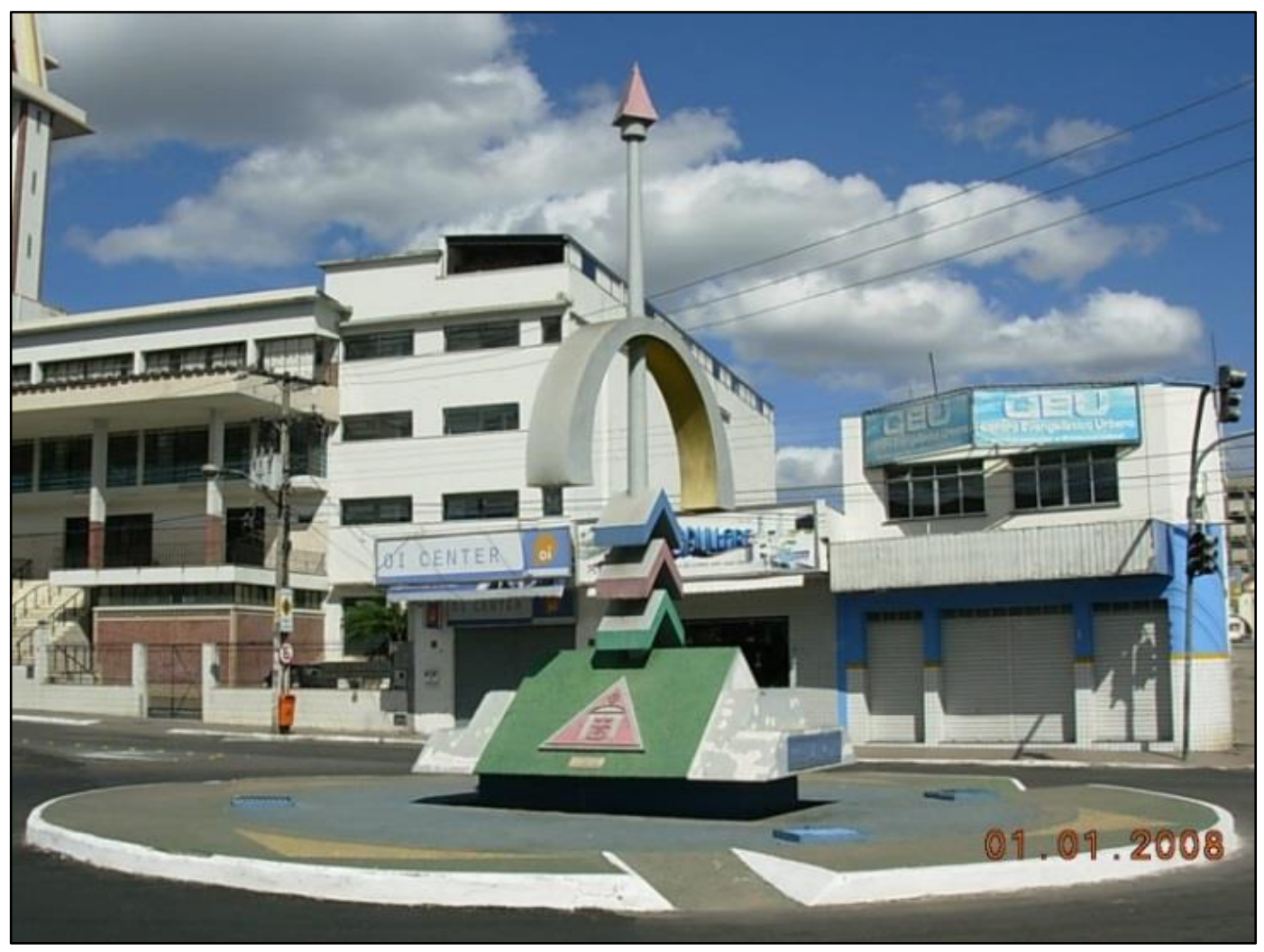

Fonte: Arquivo pessoal das autoras.

A peça, formada por uma combinação de bronze, ferro e concreto armado, está localizada numa praça cujo espaço é pouco prestigiado do ponto de vista da visibilidade, pois lá há um grande fluxo de carros circulando em volta. No que se refere, mais precisamente, a data do erguimento da peça, ao lado da comemoração oficial dos 500 anos do Brasil, este contexto também foi marcado por mobilizações coletivas de diversos segmentos da sociedade, dentre eles, de alguns grupos indígenas, os quais protestavam contra esta comemoração oficial e as teses relacionadas ao seu povo. Cabe ressaltar que esses protestos inserem-se num contexto mais amplo de afirmação do poder democrático. Podemos inferir que tal momento configura-se no que Michael Pollack chama de momento de crise. Nesse contexto, conforme as preposições deste autor, configura-se a emergência de memórias, antes marginalizadas ou excluídas, que estavam em zonas de sombra e de silêncio. Ao emergirem, estas memórias entram em evidência e, por conseguinte, em disputa, coexistindo no mesmo

27 CAIRO, A. Monumento em Homenagem ao Índio (carta). In: MORAIS, Gerlane B. Rodrigues. Monumentos de Vitória Da Conquista: Patrimônio Cultural e Discursos de Memórias. 2009. Dissertação (Mestrado em Memória Social) - Programa de Pós-graduação em Memória Social, Universidade Federal do Estado do Rio de Janeiro, Rio de Janeiro, p. 111-113. 
espaço urbano onde existiam outras memórias oficiais - como, por exemplo, as narrativas sobre os bandeirantes e sobre a santa Nossa Senhora da Vitória. Ao lado desse fenômeno, se materializam discursos que enfatizam a luta por reconhecimento da memória e a (re)construção de identidades. Conforme sublinha Michel Pollack:

A memória é um elemento constituinte do sentimento de identidade, tanto individual como, coletiva, na medida em que ela é também um fator extremamente importante do sentimento de continuidade e de coerência de uma pessoa ou de um grupo em sua reconstrução de si. ${ }^{28}$

No que se refere, mais precisamente, ao sentimento de identidade coletiva, construído com o erguimento e a promoção de monumentos, faz-se necessário reafirmar que, tanto o monumento em homenagem aos bandeirantes, quanto o monumento em homenagem à santa referem-se às memórias institucionais - forjadas pelo Estado e pela Igreja, respectivamente. Já o monumento em homenagem aos índios refere-se à memória de grupos sociais, os quais reivindicavam a legitimidade de suas memórias perante o Estado buscando, assim, se adequarem às prerrogativas de uma lógica que fundamenta uma concepção de Estado-nação moderno. Sabemos que o Estado-nação, enquanto "comunidade imaginada", ${ }^{29}$ necessita nutrir entre os seus membros um sentimento de pertencimento nacional e, para isso, busca acomodar, em certa medida, memórias antagônicas. É nessa perspectiva que a peça em homenagem aos índios emerge: numa tentativa do Estado em atenuar as contradições inerentes ao seu próprio projeto político e ideológico de sentimento de pertencimento nacional. Para isso, o Estado legitima, de certa forma, as narrativas de grupos sociais desprestigiados e marginalizados, mesmo que os lugares de memórias destes grupos sejam erigidos em espaços de pouca visibilidade - como é o caso do espaço urbano onde foi erigida a peça em homenagem aos índios. ${ }^{30}$

A despeito das condições de conflitos e contradições em que estes lugares de memórias são erigidos, de acordo com Paulo Knauss, um monumento como a peça em homenagem aos índios, cuja temática tem em sua base narrativa o sentido de exclusão, quando erigido, abre um espaço no campo simbólico que pode projetar os grupos sociais antes desprestigiados na vida urbana. ${ }^{31}$ Podemos inferir, portanto, que a partir do momento em que se erguem e que se promovem peças escultóricas, como, por exemplo, a peça em homenagem aos índios, abre-se um campo polifônico em que essas e outras memórias poderão coexistir, podendo até se integrar à memória oficial, conforme sublinha Michael Pollack. Ao lado disso, podemos dizer que se abrem outras possibilidades de leituras tanto da memória quanto da história, em que se afirmam, enquanto protagonistas, os sujeitos antes excluídos e/ou marginalizados dessa história local.

\footnotetext{
${ }^{28}$ POLLAK, M. Memória e identidade social. Revista Estudos Históricos, Rio de Janeiro, n. 10, 1992, p.5.

${ }^{29}$ ANDERSON, B. Nação e Consciência Nacional. São Paulo: Editora Ática, 1989, p.14.

${ }^{30}$ NORA, Pierre. Entre memória e história: a problemática dos lugares. Projeto História, São Paulo, PUCSP, n. 10, 1993, p. 12.

${ }^{31}$ KNAUSS, P. (coord.). Cidade vaidosa... Op. cit.
} 


\section{Considerações finais}

Em que pese o processo conflituoso, do ponto de vista material e simbólico, de consolidação da ideia de Estado-nação, que motivou a necessidade de construção de uma memória nacional e, consequentemente, de lugares de memórias, entendemos o processo de erguimento e promoção de monumentos como uma possibilidade de inserção social de grupos sociais marginalizados do tecido social urbano, possibilitando uma abertura para um espaço citadino mais democrático.

Com efeito, a partir do contexto de redemocratização do país, a cidade de Vitória da Conquista começou a agregar em seu espaço público uma diversidade de monumentos cujas bases narrativas expressam uma polifonia de discursos, onde se apresentam múltiplas memórias que coexistem - ou buscam coexistir - e, algumas, trazem novas leituras do passado, numa dinâmica social de disputas, conflitos, contradições, rupturas e continuidades. Desta forma, os monumentos em homenagem aos bandeirantes, à santa e aos índios se inscrevem em valores históricos e intencionais que representam desejos de memórias da sociedade e/ou dos grupos socais divergentes e/ou distintos. Não obstante, ainda que a base narrativa do monumento ao índio seja antagônica às construções narrativas dos outros dois monumentos, as três peças escultóricas fazem parte de um passado comum: a memória fundacional da cidade.

Podemos dizer que a promoção desses monumentos configura-se como afirmação social do poder local, num contexto nacional de autonomização política da municipalidade decorrente do processo de democratização da Constituição Federal de 1988. Nesta perspectiva, ocorre a hipótese de que essa prática se constitui num fenômeno recorrente em outras cidades brasileiras. Em que pese às tensões, os conflitos e às diferenças, cabe destacar que esse quadro de disputas de memórias no campo do patrimônio cultural só é possível onde o poder político da sociedade se configura, por excelência, numa prerrogativa e atribuição democrática. Nesse sentido, a cidade apresenta outras narrativas do passado, em que outros sujeitos, antes desprestigiados e excluídos, podem ganhar evidência no tecido social urbano, entrando em disputa para registrar-se também enquanto protagonistas da Memória e da História. 


\section{Referências Bibliográficas}

ABREU, R. A Fabricação do Imortal: memória, história e estratégias de construção no Brasil. Rio de Janeiro: Lapa; Rococó, 1996.

ABREU, R.; CHAGAS, Mário (orgs.). Memória e Patrimônio: ensaios contemporâneos. Rio de Janeiro: DP\&A, 2003.

ALMEIDA, E. Castro de. Inventário dos documentos relativos ao Brasil existentes no Arquivo de Marinha e Ultramar. Anais da Biblioteca Nacional. Lisboa, 1910-1912, v. XXXII- XXXIV; Bahia, $1763-1786$.

ANDERSON, B. Nação e Consciência Nacional. São Paulo: Ática, 1989.

CERTEAU, M. de. Relatos de Espaço. In: A invenção do Cotidiano. Petrópolis, RJ: Vozes, 1998.

CHOAY, F. A alegoria do patrimônio. Trad.: Luciano Vieira Machado. $3^{a}$ ed. São Paulo: Edições Liberdade; Ed. UNESP, 2006.

DODEBEI, V. Memória, circunstância e movimento. In: GONDAR, Jô; DODEBEI, Vera (orgs.). O que é memória social? Rio de janeiro: Contra Capa; Livraria do Programa de Pós-graduação em Memória Social da Universidade Federal do Estado do Rio de Janeiro, 2005.

GONDAR, J. Memória individual, memória coletiva, memória social. Morpheus - Revista Eletrônica em Ciências Humanas, ano 08, n. 13, 2008.

GONDAR, J. Quatro proposições sobre memória social. In: GONDAR, Jô; DODEBEI, Vera (orgs.) O que é memória social? Rio de Janeiro: Contra Capa, 2005.

HALBWCHAS, M. A memória coletiva. São Paulo: Centauro, 2006.

HOBSBAWN, E.; RANGER, T. (orgs.) A invenção das tradições. Trad.: Celina Carmem Cavalcante. Rio de Janeiro: Paz e Terra, 1984.

IVO, I. P. O Anjo da Morte contra o Santo Lenho: poder, vingança e cotidiano no sertão da Bahia. Vitória da Conquista, BA: Ed. UESB, 2004.

KNAUSS, P. (coord.) Cidade vaidosa: imagens urbanas do Rio de Janeiro. Rio de Janeiro: 7 Letras, 1999.

KNAUSS, P. Imagens urbanas e poder simbólico: esculturas e monumentos públicos nas cidades do Rio de Janeiro e de Niterói. 1998. Tese (Doutoramento em História) - Programa de Pós-graduação em História, Universidade Federal Fluminense, Niterói, RJ.

KNAUSS, P. O Sorriso da Cidade: imagens urbanas e história política de Niterói. Niterói, RJ: Fundação de Arte de Niterói, 2003.

LE GOFF, J. Memória e história. Campinas: Ed.Unicamp, 1990.

LIMA, J. M. Memorial sobre o Estado da Bahia. Salvador: Topografia e encadernação do Diário da Bahia, 1893.

MORAIS, Gerlane B. Rodrigues. Monumentos de Vitória Da Conquista: Patrimônio Cultural e Discursos de Memórias. 2009. Dissertação (Mestrado em Memória Social) - Programa de Pós-graduação em Memória Social da Universidade Federal do Estado do Rio de Janeiro, Rio de Janeiro. 
NORA, P. Entre memória e história: a problemática dos lugares. Projeto História, São Paulo, PUC-SP, n. $10,1993$.

POLLAK, Michael. Memória e identidade social. Revista Estudos Históricos, Rio de Janeiro, v. 5, n. 10, 1992.

POMIAN, Krizystof. Coleção. (Verbete). In: Enciclopédia Einaudi. Vol. 1: Memória - História. Lisboa: Imprensa Nacional - Casa da Moeda, 1984, p.51-86.

RICOEUR, Paul. Entre mémoire et I'histoire. Projet, Paris, n. 248, 1996.

RIEGEL, Alöis. O Culto Moderno dos Monumentos: sua essência e sua gênese. Goiânia: Ed. UGG: Goiânia, 2006.

TORRES, T. L. O Município da Vitória. Vitória da Conquista, BA: Museu Regional da Vitória da Conquista; Universidade Estadual do Sudoeste da Bahia, 1996.

VERNANT, Jean-Pierre. As Origens do Pensamento Grego. São Paulo: Difel, 2002.

VIANA, Aníbal Lopes. Revista histórica de Conquista. Vitória da Conquista, BA: Edição Jornal de Conquista, 1982.

WIED-NEUWIED, M. Viagem ao Brasil. Belo Horizonte; São Paulo: Itatiaia; Ed. USP, 1989. 